\title{
Recent advances and perspectives in ruthenium-catalyzed cyanation reactions
}

\author{
Thaipparambil Aneeja, Cheriya Mukkolakkal Abdulla Afsina, Padinjare Veetil Saranya \\ and Gopinathan Anilkumar*
}

Open Access

\author{
Review \\ Address: \\ School of Chemical Sciences, Mahatma Gandhi University, PD Hills, \\ Kottayam, Kerala, 686560, India \\ Email: \\ Gopinathan Anilkumar* - anilgi1@yahoo.com \\ * Corresponding author \\ Keywords: \\ cyanation; nitriles; photocatalyst; ruthenium; tertiary amines
}

\author{
Beilstein J. Org. Chem. 2022, 18, 37-52. \\ https://doi.org/10.3762/bjoc.18.4 \\ Received: 28 July 2021 \\ Accepted: 16 December 2021 \\ Published: 04 January 2022 \\ Associate Editor: I. Marek \\ (C) 2022 Aneeja et al.; licensee Beilstein-Institut. \\ License and terms: see end of document.
}

\begin{abstract}
The cyanation reaction has achieved rapid progress in recent times. The ability to exhibit multiple oxidation states increased the demand of ruthenium in the field of catalysis. These cyanation reactions have wide application in pharmacological and biological fields. This review gives an overview of the ruthenium-catalyzed cyanation reactions covering literature up to 2021 .
\end{abstract}

\section{Introduction}

Nitriles are a major class of organic compounds having wide significance in materials science, agrochemical and pharmaceutical industry [1]. They are the privileged compounds finding broad applications in natural product synthesis, pigments and dyes.

Different variety of $\alpha$-amino carbonyls [2], $\alpha$-amino acids [3] and 1,2-diamines were prepared from the nitriles using homogeneous and heterogeneous catalysis [4-6]. One of the astonishing aspects of nitriles is that it can be easily converted to amines, carboxylic acids, tetrazoles, aldehydes, amidines, and amides [7-11]. This has been suitably transformed into structurally diverse and complex molecules.
In 1927, Pongratz reported a method towards cyanation reactions [12]. From then, onwards, cyanation gained prime focus and achieved much acceptance. The conventional approaches towards the synthesis of nitriles include Rosenmund-von Braun reactions, Sandmeyer reactions and industrial ammoxidation reactions $[13,14]$. But these strategies involve harsh reaction conditions and generation of large amount of heavy metal waste. These drawbacks demanded the need of an alternative method for the synthesis of nitriles.

Nowadays transition-metal-catalyzed reactions have received tremendous interest. Various transition metals such as Fe [15], Co [16], Ni [17], Pd [18], Cu [19], Rh [20] etc. were well 
explored in cyanation owing to its cost-effective and earth abundant characteristics. Moreover, much greener methodologies like microwave-assisted cyanation reactions also received much attention in recent times [21].

The cyanation can be carried out using electrophilic and nucleophilic cyanating agents [22]. Usually a cyanation is accomplished via the nucleophilic attack of a $\mathrm{CN}^{-}$at an electrophilic carbon center. But there are some reagents that react as $\mathrm{CN}^{+}$ and thus attack the nucleophilic carbon center. Tosyl cyanide [23], 2-chlorobenzylthiocyanate [24], and cyanogen chloride [25] are some of the examples for electrophilic cyanating agents. Commonly used metallic cyanating agents include $\mathrm{K}_{4} \mathrm{Fe}(\mathrm{CN})_{6}, \mathrm{CuCN}, \mathrm{KCN}, \mathrm{NaCN}, \mathrm{TMSCN}$ etc.

Ruthenium-catalyzed reactions have gained significant attention in recent times [26]. Ruthenium has the ability to show a large number of oxidation states, and thus a large number of complexes can be prepared using this metal. Ruthenium complexes have astonishing characteristics such as high electron transfer ability, low redox potentials, high Lewis acidity, and greater stabilities of the reactive metallic species like oxometals, metallacycles, and metal carbene complexes [27]. The wide availability of highly reactive ruthenium complexes which are efficient as catalysts elevated the scope of this metal in synthetic organic chemistry.

For clarity and ease of understanding of the topic, this review is categorized into four sections: cyanation of amines, cyanation of arenes and heteroarenes, photocatalyzed cyanation, and miscellaneous. To the best of our knowledge, this is the first review summarizing an overview of ruthenium-catalyzed cyanation reactions covering literature up to 2021 .

\section{Review}

\section{Cyanation of amines}

\subsection{Cyanation of amines using heterogeneous catalysts}

Sain and co-workers investigated the ability of starch-immobilized ruthenium trichloride to catalyze the oxidative cyanation of tertiary amines [28]. The reaction was performed using $2 \mathrm{~mol} \%$ of catalyst, $2.5 \mathrm{mmol} \mathrm{H}_{2} \mathrm{O}_{2}, 1.2 \mathrm{mmol} \mathrm{NaCN}$, and $1 \mathrm{~mL} \mathrm{CH}_{3} \mathrm{COOH}$ in methanol at room temperature (Scheme 1). Better yields of the $\alpha$-aminonitrile products were obtained for aromatic amines with electron-donating substituents than electron-withdrawing ones. Under the optimized conditions, tributylamine was found inactive to afford the desired product. Inductively coupled plasma atomic emission spectroscopy (ICPAES) analysis confirmed the purity of the prepared compounds without any ruthenium contamination. The attractive features of this reaction include environment-friendly conditions, effective recycling and activity of the catalyst, and high product selectivity. A plausible mechanism of this transformation is depicted in Scheme 2.

Later in 2012, Nageswar et al. have established a methodology for the oxidative cyanation of tertiary amines using a heterogeneous $\mathrm{Ru} / \mathrm{C}$ catalyst [29]. Most of the reported works involve the

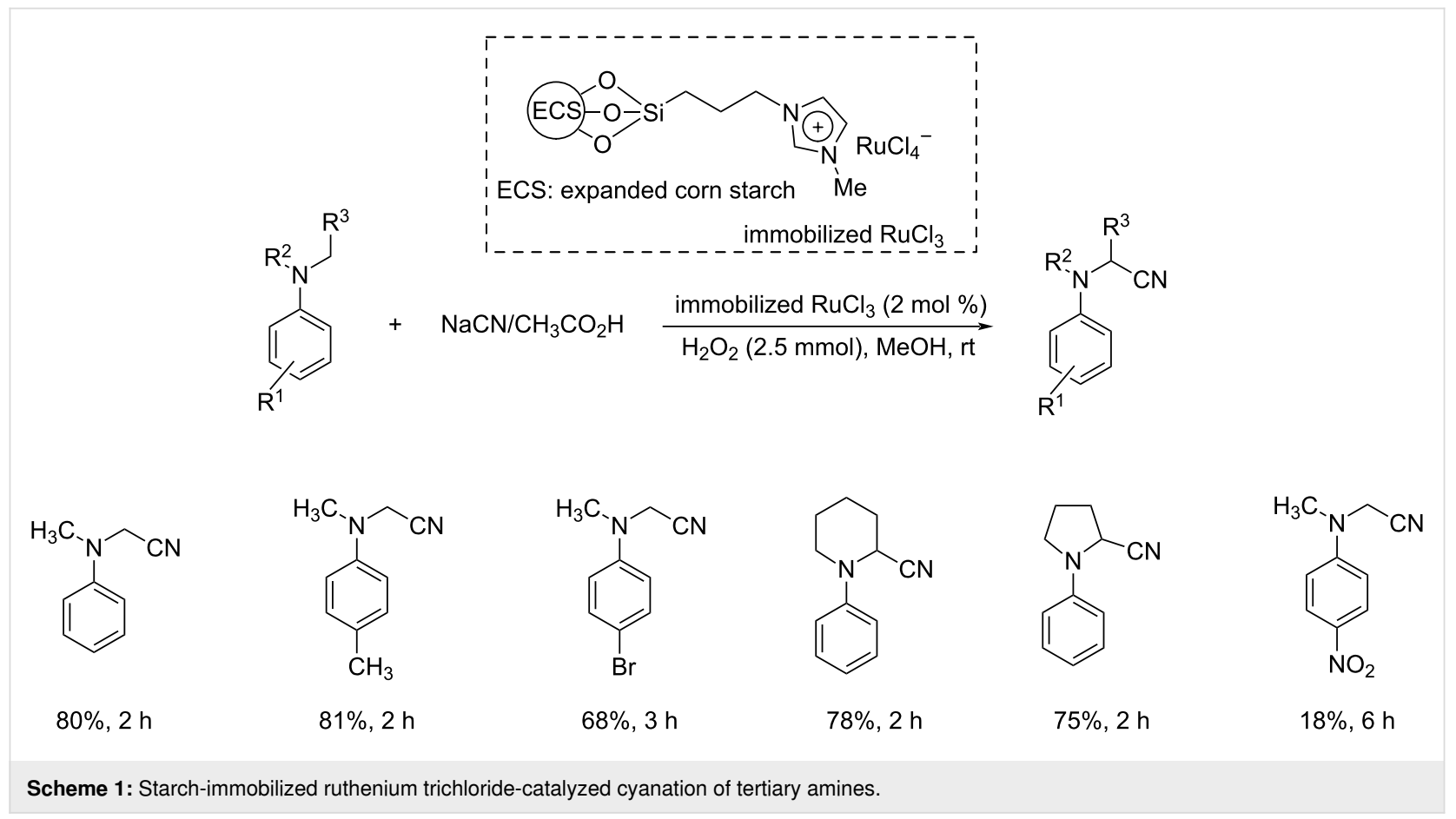




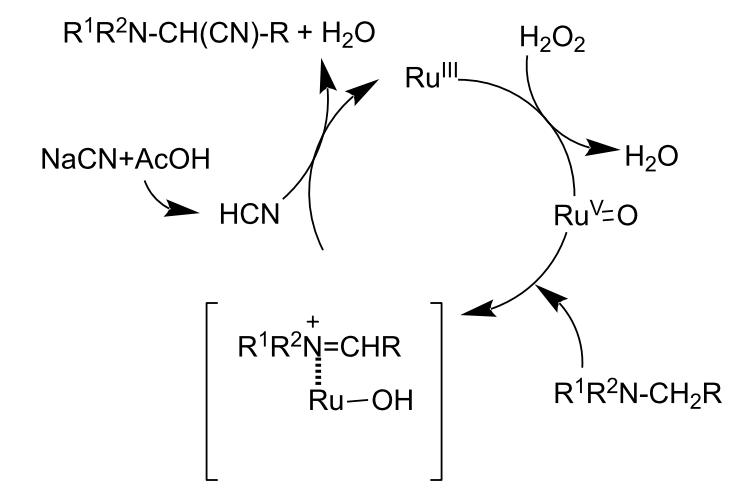

Scheme 2: Proposed mechanism for the cyanation of tertiary amines using starch-immobilized ruthenium trichloride as the catalyst.

use of toxic cyanating agents like $\mathrm{NaCN}$ or TMSCN. In this protocol, the authors have exploited the cost-effective, less toxic, and easily available ethyl cyanoformate as the cyanide source. They carried out the optimization studies using $N, N$ dimethylaniline $(1.0 \mathrm{mmol})$ and ethyl cyanoformate $(2.0 \mathrm{mmol})$ as the model substrates and the optimized conditions include 5 wt $\% \mathrm{Ru} / \mathrm{C}(20 \mathrm{mg})$ as catalyst and 2.5 equiv of TBHP (in decane) as oxidant in methanol at $60{ }^{\circ} \mathrm{C}$ for $6 \mathrm{~h}$ (Scheme 3). Differently substituted tertiary amines with electron-rich and electron-deficient substituents afforded the required products in good yields. This reaction was found to be suitable for $N$-arylsubstituted cyclic amines such as $\mathrm{N}$-arylpiperidine, $\mathrm{N}$-arylpyrrolidine, and $N$-aryltetrahydroisoquinoline. However, aliphatic tertiary amines failed to achieve the desired product by this method. The proposed mechanism is initiated with the formation of a $\mathrm{Ru}-\mathrm{oxo}$ species by the reaction between $\mathrm{Ru} / \mathrm{C}$ and TBHP. The next step involves the formation of an iminium ion intermediate through reaction of the Ru-oxo species with the tertiary amine. The subsequent reaction between this iminium ion intermediate and $\mathrm{CN}^{-}$furnishes the required product (Scheme 4).

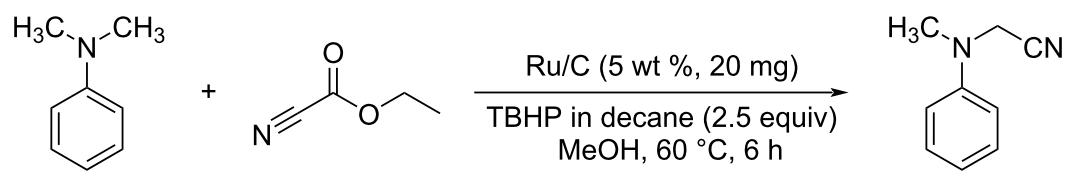<smiles>Cc1ccc(N(C)CC#N)cc1</smiles>

$95 \%$<smiles>CN(CC#N)c1ccc(Br)cc1</smiles>

$86 \%$<smiles>CN(CC#N)c1cccc2ccccc12</smiles>

$83 \%$<smiles>N#CC1CCCN1c1ccccc1</smiles>

$76 \%$<smiles>CCc1ccc(N2CCCCC2C#N)cc1</smiles>

91\%<smiles>N#Cc1ccc(N2CCCCC2C#N)cc1</smiles>

$85 \%$

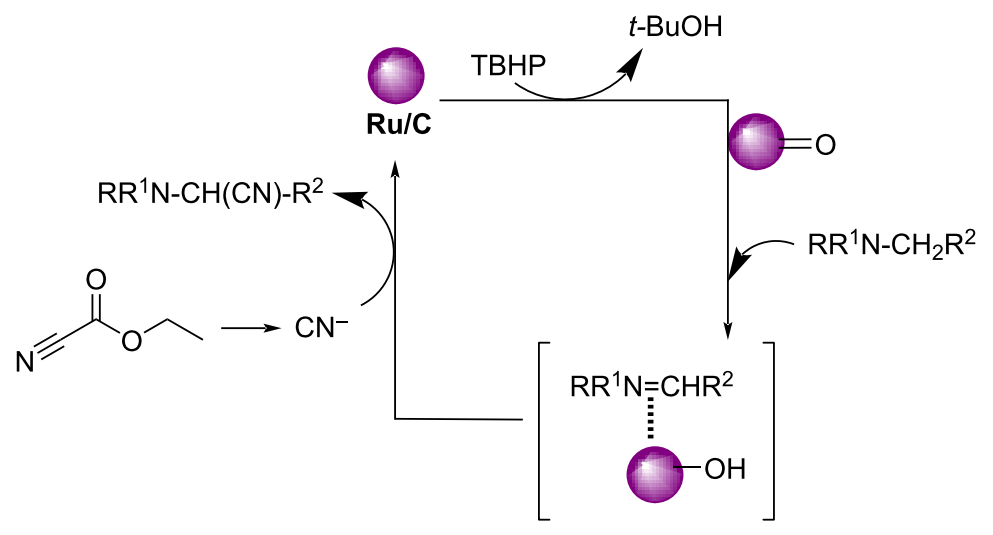


In 2013, Jain and co-workers described a novel strategy for the synthesis of a ruthenium-carbamato complex and its promising catalytic application in the oxidative cyanation reaction [30] The prepared catalyst was found highly active in the oxidative cyanation of tertiary amines to the corresponding $\alpha$-aminonitriles in excellent yields. The cyanation reaction of $N, N$ dimethylaniline using $\mathrm{NaCN}$ catalyzed by ruthenium-carbamato complex in $\mathrm{AcOH} / \mathrm{MeOH}$ furnished the desired product in $92 \%$ yield within $2.5 \mathrm{~h}$ (Scheme 5). Meanwhile, the ruthenium chloride-catalyzed cyanation reaction required $3.5 \mathrm{~h}$ to complete the reaction and achieved the product in $90 \%$ yield. Thus, the studies revealed the higher efficiency of the rutheniumcarbamato complex in catalyzing the cyanation reaction. This strategy utilized eco-friendly hydrogen peroxide and molecular oxygen as the oxidant system. This method was found highly favorable to tertiary amines with electron-donating substituents.

The first report on an MCM-41-immobilized $N$-alkylethylenediamine $\mathrm{Ru}(\mathrm{III})$ complex (MCM-41-2N-RuCl 3 ) catalyzed oxidative cyanation of tertiary amines was achieved by Cai et al [31]. The optimized conditions were MCM-41-2N-RuCl 3 (5 mol \%), NaCN (1.2 mmol), AcOH $(6.0 \mathrm{mmol}), \mathrm{H}_{2} \mathrm{O}_{2}$ $\left(2.5 \mathrm{mmol}\right.$ ) in methanol at $60{ }^{\circ} \mathrm{C}$ under $\mathrm{Ar}$ atmosphere for $4 \mathrm{~h}$ (Scheme 6). The reaction proceeded smoothly for $N$-aryl-substituted cyclic tertiary amines including $N$-arylpiperidines and $\mathrm{N}$-aryltetrahydroisoquinolines. The high reusability of the catalyst at least seven times further enhanced the importance of this strategy in the field of organic synthesis.

\subsection{Cyanation of amines using homogeneous catalysts}

An interesting ruthenium-catalyzed oxidative cyanation of tertiary amines using molecular oxygen was reported by Murahashi and co-workers [32]. This $\mathrm{RuCl}_{3} \cdot n \mathrm{H}_{2} \mathrm{O}$-catalyzed protocol used $\mathrm{NaCN}$ in acetic acid as the cyano source, methanol as the solvent under molecular oxygen at $60{ }^{\circ} \mathrm{C}$ for $1-2 \mathrm{~h}$ (Scheme 7). The extensive substrate scope studies under optimized conditions disclosed that differently substituted $N, N$ dimethylanilines gave the desired products in excellent yields. The reaction was also found suitable for $N$-phenyltetrahydroisoquinoline and delivered the expected product in good yields.

Later, the same group reported a novel synthetic pathway for the oxidative cyanation of tertiary amines using sodium cyanide [33]. The optimized conditions for this reaction included the use of $0.05 \mathrm{mmol}$ of $\mathrm{RuCl}_{3}$ as the catalyst, $1.2 \mathrm{mmol}$ of $\mathrm{NaCN}$ in acetic acid as the cyanide source and $2.5 \mathrm{mmol}$ of $\mathrm{H}_{2} \mathrm{O}_{2}$ as the oxidant in methanol (Scheme 8). Both, substituted $N, N$ dimethylanilines with electron-donating and electron-withdrawing groups were well tolerated in this reaction. The $N$-arylsubstituted cyclic amines such as $N$-arylpiperidine, $N$-aryltetrahydroisoquinoline and $\mathrm{N}$-arylpyrrolidine derivatives also reacted well to furnish the desired products in good yields.

In 2008, they described the scope and mechanism of the oxidative cyanation of tertiary amines using $\mathrm{H}_{2} \mathrm{O}_{2}$ and $\mathrm{O}_{2}$ [34]. They pointed out the fact that the hydrogen peroxide system was

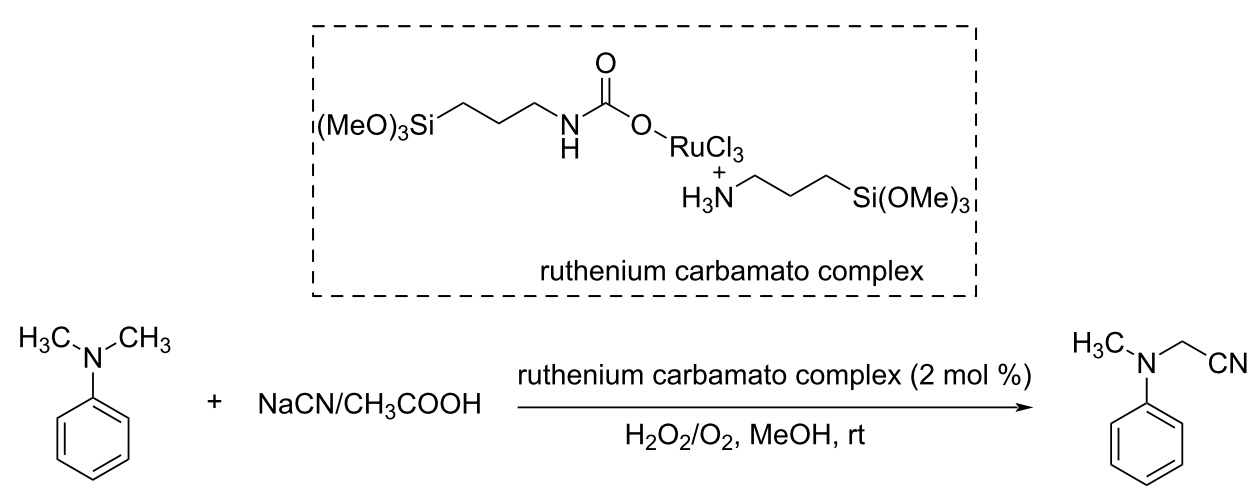<smiles>CN(CC#N)c1ccccc1</smiles>

A: $92 \%$

B: $85 \%$<smiles>Cc1ccc(N(C)CC#N)cc1</smiles>

A: $94 \%$ B: $89 \%$<smiles>Cc1cccc(N(C)CC#N)c1</smiles>

A: $92 \%$

B: $85 \%$<smiles>CN(CC#N)c1ccc(Br)cc1</smiles>

A: $70 \%$ B: $62 \%$<smiles>N#CC1CCCCN1c1ccccc1</smiles>

A: $90 \%$
B: $74 \%$<smiles>N#CC1c2ccccc2CCN1c1ccccc1</smiles>

A: $82 \%$

B: $75 \%$
A: $\mathrm{H}_{2} \mathrm{O}_{2}$ B: $\mathrm{O}_{2}$ 


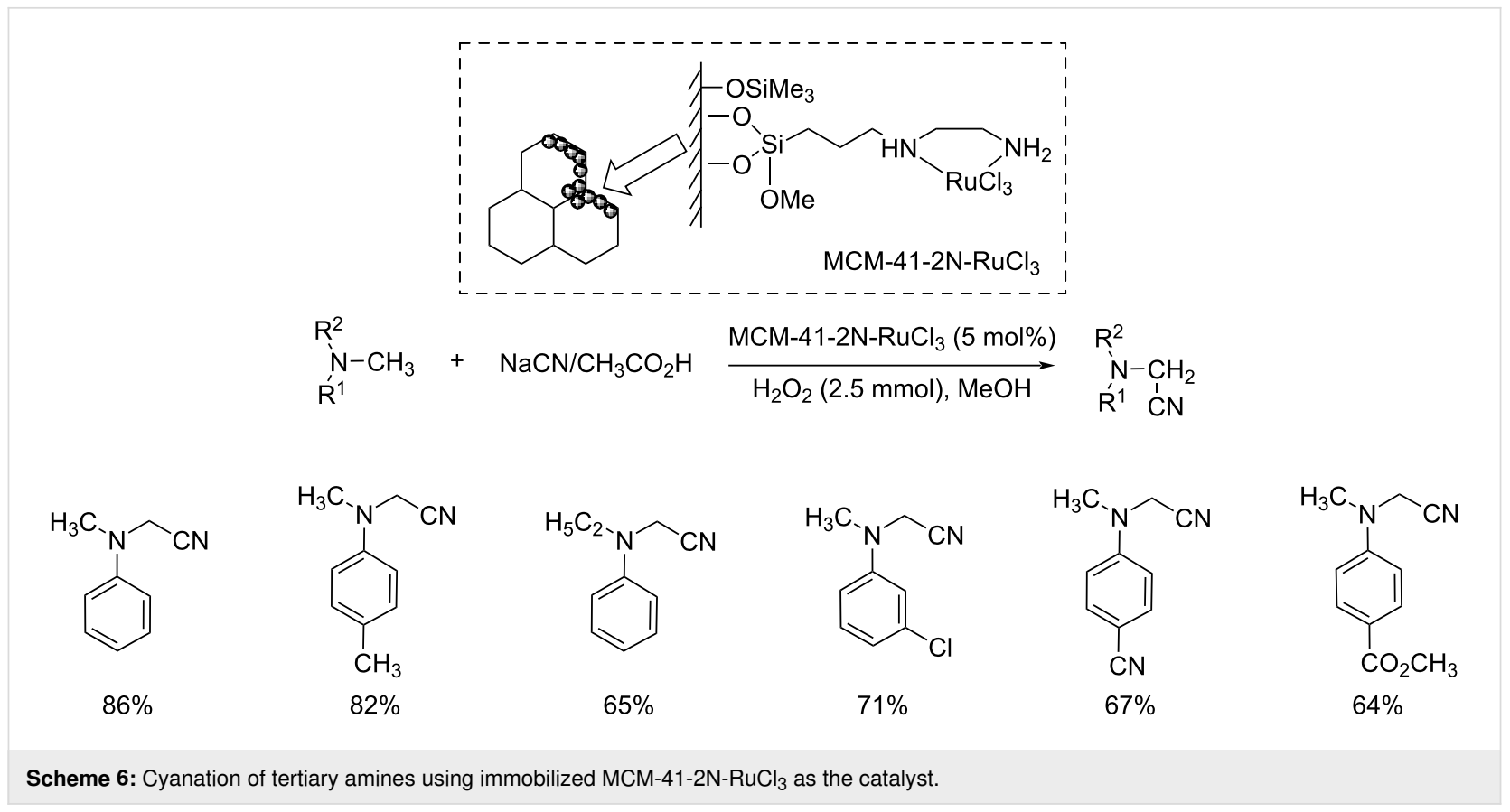

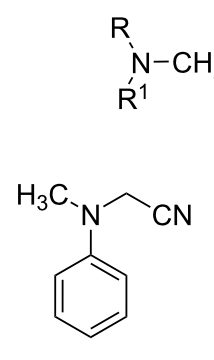

$88 \%, 2 \mathrm{~h}$

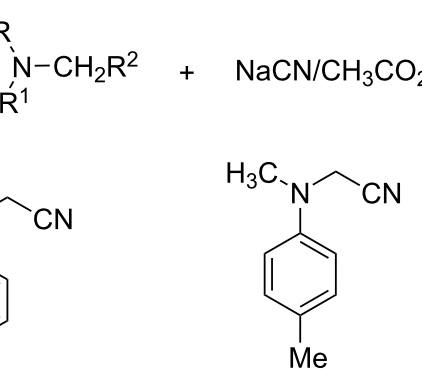

$94 \%, 1 \mathrm{~h}$

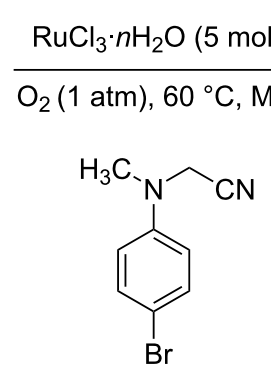

$88 \%, 2 \mathrm{~h}$
R $\mathrm{N}-\mathrm{H}-\mathrm{R}^{2}$

$\mathrm{R}^{1} \mathrm{CN}$<smiles>N#CC1c2ccccc2CCN1c1ccccc1</smiles>

$76 \%, 4 \mathrm{~h}$

Scheme 7: Cyanation of tertiary amines using $\mathrm{RuCl}_{3} \cdot \mathrm{nH}_{2} \mathrm{O}$ as the catalyst and molecular oxygen as oxidant.

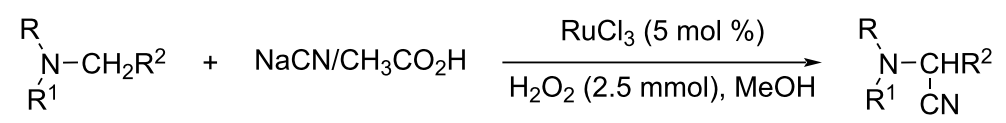<smiles>CN(CC#N)c1ccccc1</smiles>

$90 \%, 2 \mathrm{~h}$<smiles>Cc1ccc(N(C)CC#N)cc1</smiles>

$81 \%, 1.5 \mathrm{~h}$<smiles>CN(CC#N)c1ccc(Br)cc1</smiles>

$67 \%, 3 \mathrm{~h}$<smiles>COc1ccc(N(C)CC#N)cc1</smiles>

$73 \%, 1.5 \mathrm{~h}$<smiles>N#CC1CCCCN1c1ccccc1</smiles>

$69 \%, 2 \mathrm{~h}$<smiles>CCN(CC)c1ccccc1</smiles>

$63 \%, 1.5 \mathrm{~h}$<smiles>N#CC1c2ccccc2CCN1c1ccccc1</smiles>

$83 \%, 1.5 \mathrm{~h}$

Scheme 8: $\mathrm{RuCl}_{3}$-catalyzed cyanation of tertiary amines using $\mathrm{NaCN} / \mathrm{HCN}$ and $\mathrm{H}_{2} \mathrm{O}_{2}$ as oxidant.

found to be more efficient in catalyzing the cyanation reaction of cyclic amines than the aerobic oxidation system. The catalytic cycle for the hydrogen peroxide system involves the forma- tion of the oxoruthenium species (A) and the low-valent ruthenium species (B), whereas the aerobic oxidation system includes $\mathrm{C}-\mathrm{H}$ activation and a subsequent reaction with molecu- 
lar oxygen (Scheme 9 and Scheme 10). Thus, the authors came to the conclusion that the higher yields of cyanation product obtained in the case of the hydrogen peroxide system was due to the highly reactive oxoruthenium species and low-valence ruthenium species.

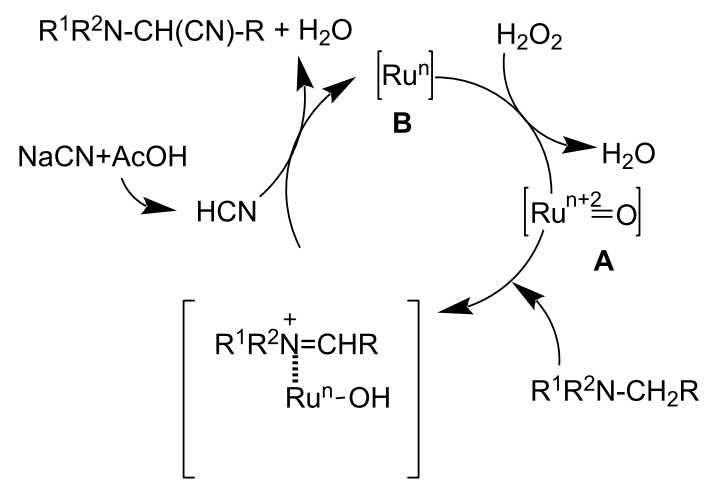

Scheme 9: Proposed mechanism for the ruthenium-catalyzed oxidative cyanation using $\mathrm{H}_{2} \mathrm{O}_{2}$
Sain et al. disclosed a new methodology towards the oxidative cyanation of tertiary amines using $\mathrm{Ru}$ as the catalyst (Scheme 11) [35]. In this reaction, the comparatively safer acetone cyanohydrin was utilized as the cyanating agent. Better yields of products were obtained for both electron-rich and electron-deficient tertiary amines. Cyclic amines such as piperidine, tetrahydroisoquinoline derivatives, and pyrrolidine were also tolerated well in this reaction. The use of the non-toxic and inexpensive acetone cyanohydrin makes this method more advantageous compared to the known methods.

\section{Cyanation of arenes and heteroarenes 2.1 Cyanation of arenes and heteroarenes using heterogeneous catalysts}

In 2012, a novel strategy for the 3-cyanation of indole in the presence of $\mathrm{Ru}(\mathrm{III})$-exchanged $\mathrm{NaY}$ zeolite (RuY) was reported [36]. In this reaction $\mathrm{K}_{4}\left[\mathrm{Fe}(\mathrm{CN})_{6}\right]$ was utilized as the cyano source in DMF at $110^{\circ} \mathrm{C}$. The $\mathrm{Cu}(\mathrm{OAc})_{2}$ and $\mathrm{O}_{2}(1 \mathrm{~atm})$ was found essential for promoting this reaction (Scheme 12). Both electron-rich and electron-deficient indoles afforded the desired

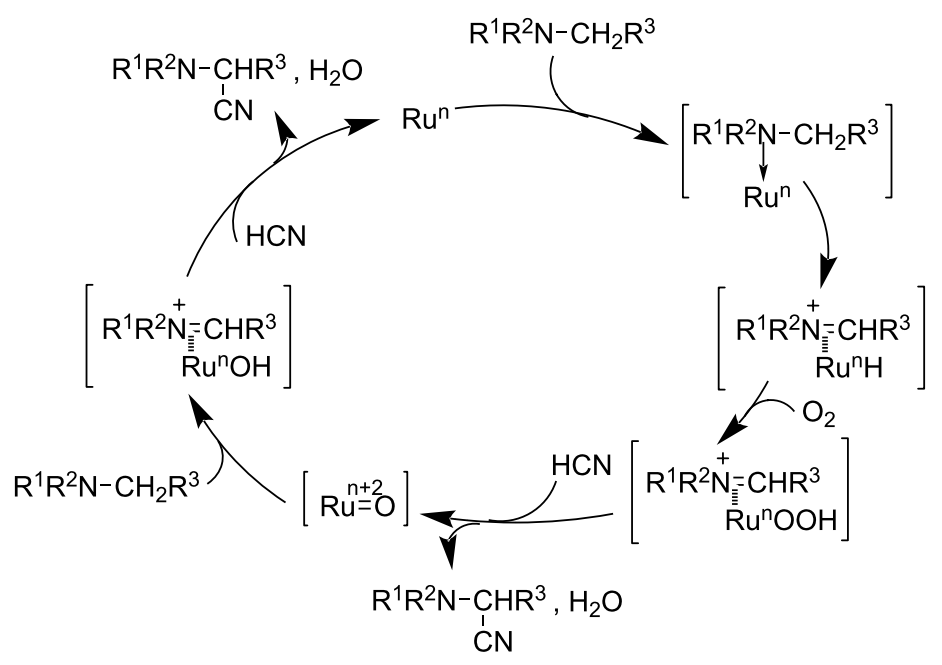

Scheme 10: Proposed mechanism for the ruthenium-catalyzed aerobic oxidative cyanation.

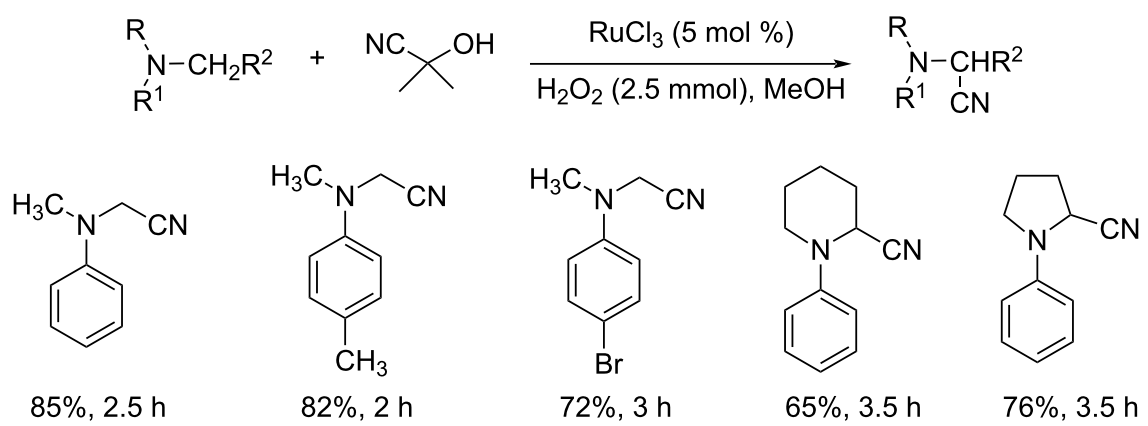

Scheme 11: $\mathrm{RuCl}_{3}$-catalyzed oxidative cyanation of tertiary amines using acetone cyanohydrin as the cyanating agent. 


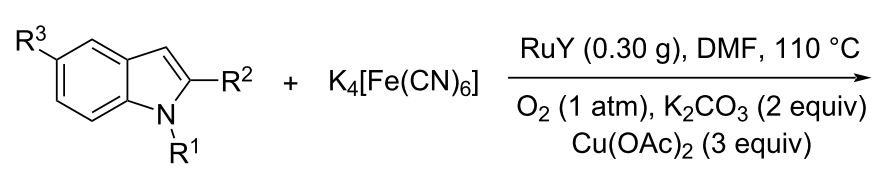<smiles>[R]c1ccc2[nH]c([R])c(C#N)c2c1</smiles><smiles>Cc1[nH]c2ccccc2c1C#N</smiles>

$70 \%$<smiles>Cn1cc(C#N)c2ccccc21</smiles>

$71 \%$<smiles>N#Cc1c[nH]c2ccc(Cl)cc12</smiles>

$63 \%$<smiles>Cc1c(C#N)c2ccccc2n1C</smiles>

$77 \%$<smiles>COc1ccc2[nH]cc(C#N)c2c1</smiles>

$66 \%$<smiles>N#Cc1c(-c2ccccc2)[nH]c2ccccc12</smiles>

$64 \%$

Scheme 12: Cyanation of indoles using $\mathrm{K}_{4}\left[\mathrm{Fe}(\mathrm{CN})_{6}\right]$ as cyano source and $\mathrm{Ru}(\mathrm{III})$-exchanged NaY zeolite (RuY) as catalyst.

products in good yields. The major advantages of this method include high regioselectivity, mild reaction conditions, and reusability of the catalyst.

Two years later, in 2014, Ackermann and co-workers disclosed an astonishing protocol towards the cyanation of arenes and heteroarenes using a ruthenium(II) catalyst [37]. This was the first report on a $\mathrm{C}\left(\mathrm{sp}^{2}\right)-\mathrm{H}$ cyanation reaction using ruthenium as the catalyst. In this reaction the authors utilized the less toxic, environment-friendly, and easily available $N$-cyano- $N$-phenyl$p$-toluenesulfonamide (NCTS) as the cyanating reagent. The reaction exhibited high chemoselectivity and good functional group tolerance. The optimized conditions for the reaction were $\left[\mathrm{RuCl}_{2}(p \text {-cymene) }]_{2}(5 \mathrm{~mol} \%), \mathrm{AgSbF}_{6}(20 \mathrm{~mol} \%), \mathrm{NaOAc}\right.$ $\left(20 \mathrm{~mol} \%\right.$ ) in DCE at $120{ }^{\circ} \mathrm{C}$ for $24 \mathrm{~h}$ (Scheme 13). Differently substituted aromatic amides with a range of functional groups such as fluoro, chloro, bromo, ester etc. were tolerated well in this method. The authors also performed the cyanation of heteroarenes at C-2 and C-3 positions and obtained excellent results. Various heteroarenes such as thiophenes, benzofurans, furans, and indoles were found suitable substrates and afforded the desired products with high chemo- and site-selectivity. A possible mechanism for the reaction was also described. The first step of the catalytic cycle involves the formation of a

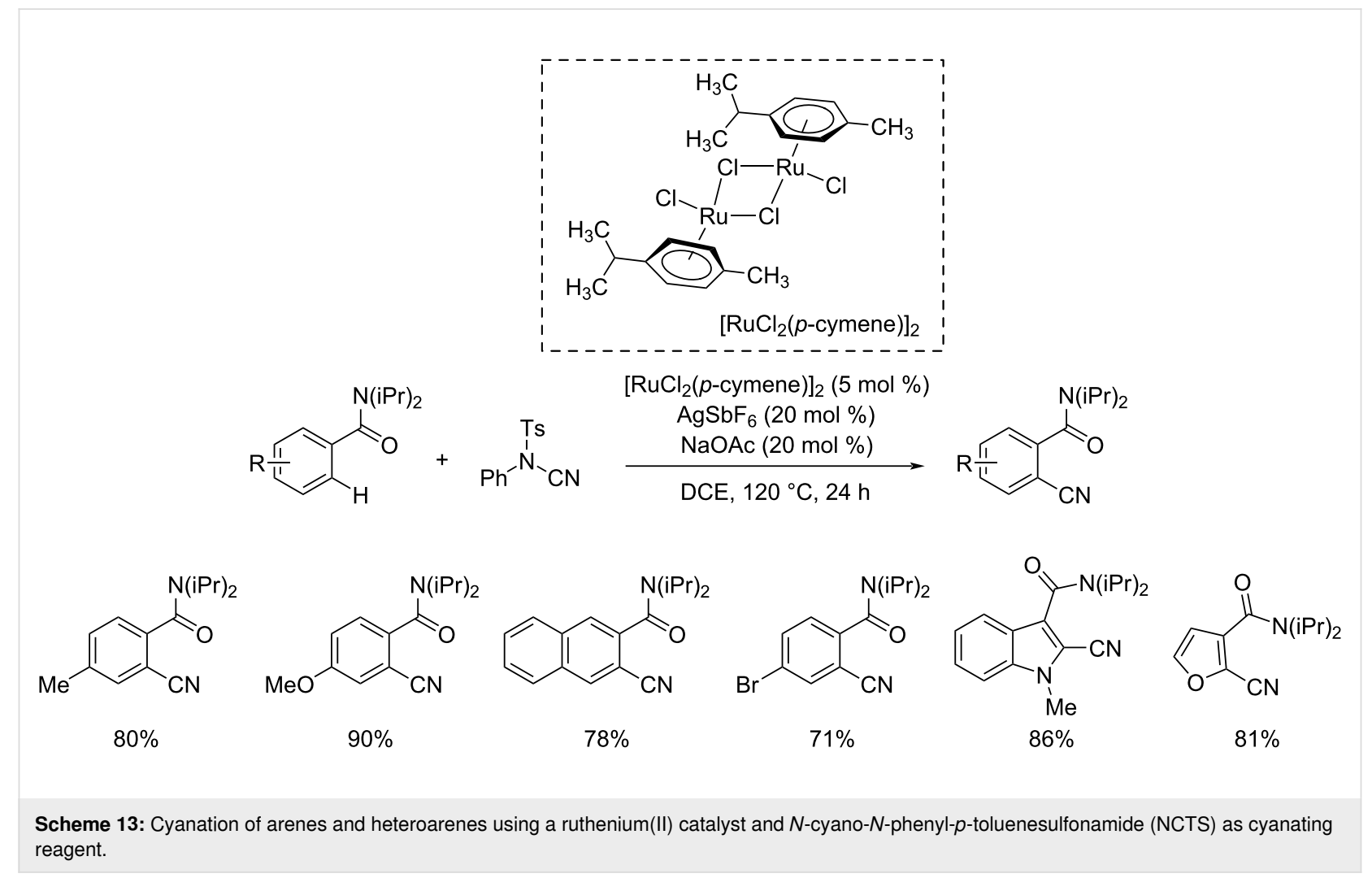


cationic complex I which after coordination and subsequent NCTS insertion is transformed to intermadiate II. $\beta$-Elimination finally delivers the required product (Scheme 14).

Later, Deb and co-workers developed a methodology towards the synthesis of $N$-(2-cyanoaryl)-7-azaindoles using $\left[\mathrm{RuCl}_{2}(p\right.$ cymene) $]_{2} / \mathrm{AgOTf} / \mathrm{NaOAc}$ as the catalyst system (Scheme 15) [38]. They carried out extensive substrate scope studies and it was pointed out that $N$-aryl-7-azaindoles substituted with electron-donating groups gave better yields of products. Heteroarenes also performed well in this reaction with high reactivity. The authors also investigated the cyanation of differently substituted 7-azaindoles and achieved excellent results. They also succeeded in applying this strategy to $N$-aryl- $\alpha$-carbolines to synthesize the respective cyanated $N$-aryl- $\alpha$-carboline products.

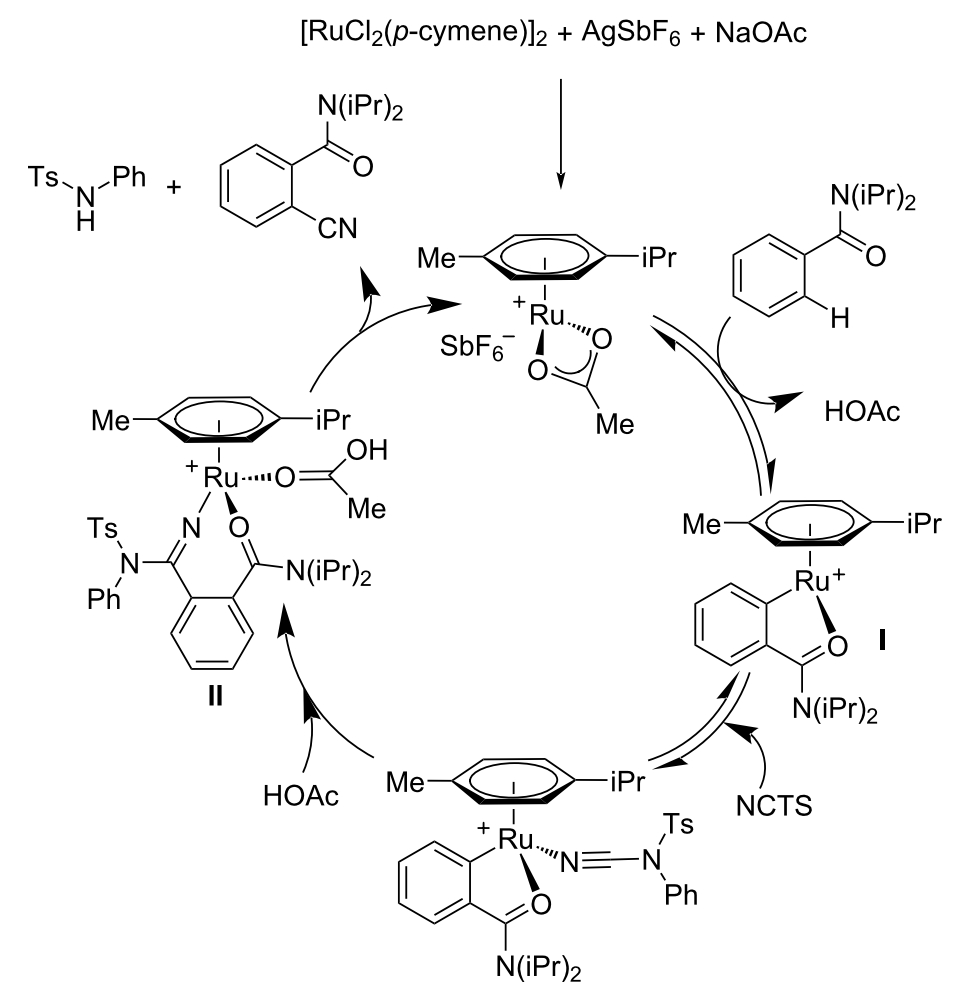

Scheme 14: Proposed mechanism for the cyanation of arenes and heteroarenes using ruthenium(II) as catalyst and NCTS as cyanation reagent.

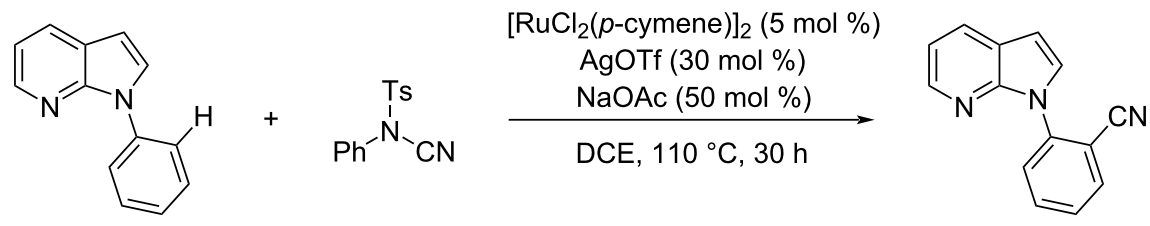<smiles>Cc1ccc(C#N)c(-n2ccc3cccnc32)c1</smiles>

$81 \%$<smiles>CN(C)c1ccc(C#N)c(-n2ccc3cccnc32)c1</smiles>

$83 \%$<smiles>COc1ccc(C#N)c(-n2ccc3cccnc32)c1</smiles>

$75 \%$<smiles>CC(=O)c1cccc(C#N)c1-n1ccc2cccnc21</smiles>

$66 \%$<smiles>N#Cc1ccc2ccccc2c1-n1ccc2cccnc21</smiles>

$78 \%$<smiles>N#Cc1ccoc1-n1ccc2cccnc21</smiles>

$64 \%$ 


\section{Photocatalyzed cyanation reactions}

Nowadays photocatalysis has emerged as an efficient tool for the synthesis of organic compounds. Jain et al. put forward an oxidative cyanation of tertiary amines using an immobilized heterogeneous ruthenium catalyst (Figure 1) [39]. The optimized conditions comprised sodium cyanide $(\mathrm{NaCN})$ $(1.2 \mathrm{mmol})$ in acetic acid as cyanide source, molecular oxygen as the oxidant, and $\mathrm{TiO}_{2}$-immobilized ruthenium(II) polyazine complex as the heterogeneous photoredox catalyst in methanol at room temperature (Table 1). The substrate scope studies revealed a better reactivity of aromatic tertiary amines substituted with electron-donating groups compared to the electronwithdrawing ones. The $N$-aryl cyclic amines including $\mathrm{N}$-phenylpiperidine, $\mathrm{N}$-phenyltetrahydroisoquinoline, and $\mathrm{N}$-phenylpyrrolidine smoothly reacted to deliver the required $\alpha$-aminonitriles in good yields. Under the optimized conditions, aliphatic tributylamine failed to achieve the desired product (Table 1, entry 5). However, tertiary amines with a benzyl group reacted very slowly and afforded the expected product in moderate yield (Table 1, entry 6). The reason for the incompatibility of tributylamine towards this method has yet to be explored.

A synthesis of allylic cyanides via visible-light-mediated oxidative cyanation of aza-Baylis-Hillman adducts was developed by Yadav and co-workers [40]. The cyanating agent employed was TMSCN in acetonitrile (Scheme 16). The aza-BH adducts with electron-donating groups gave higher yields in comparison with electron-deficient ones. Mild reaction conditions, readily available reagents, lower catalyst loading, and the use of cost effective atmospheric oxygen and visible light are the most attractive characteristics of this reaction.

$\mathrm{Xu}$ et al. in 2016 discussed the deboronative cyanation of alkyltrifluoroborates using $\left[\mathrm{Ru}(\mathrm{bpy})_{3}\right]\left(\mathrm{PF}_{6}\right)_{2}$ as the photoredox catalyst [41]. This method provides an efficient pathway to $1^{\circ}, 2^{\circ}$, and $3^{\circ}$ alkyl nitriles using $p$-toluenesulfonyl cyanide (TsCN) in $\mathrm{CH}_{2} \mathrm{Cl}_{2} / \mathrm{H}_{2} \mathrm{O}$ under visible-light irradiation (Scheme 17). 1-Acetoxy-1,2-benziodoxol-3-(1H)-one (BI-OAc) was chosen as the oxidant and TFA as the additive in this method. A lower reactivity was observed for $2^{\circ}$ and $3^{\circ}$ alkyltrifluoroborates under the optimized conditions. The authors were able to improve the product yield by increasing the amount of TsCN and avoiding the use of additive (Scheme 18). A wide variety of functional groups such as esters, cyano, amides, ethers, ketones, alkynes, and halides were compatible with this strategy.

A photoredox-catalyzed oxidative coupling of 4-alkyl-3,4-dihydroquinoxalin-2(1H)-ones with nucleophiles was reported by Hong and co-workers [42]. The reaction was performed using $20 \mathrm{~mol} \%$ of $\mathrm{Ru}(\mathrm{bpy})_{3} \mathrm{Cl}_{2} \cdot 6 \mathrm{H}_{2} \mathrm{O}$ in methanol under CFL light irradiation at room temperature (Scheme 19). They were able to synthesize the cyano derivative by utilizing TMSCN as the cyanating medium, and obtained the desired product in $74 \%$ yield.

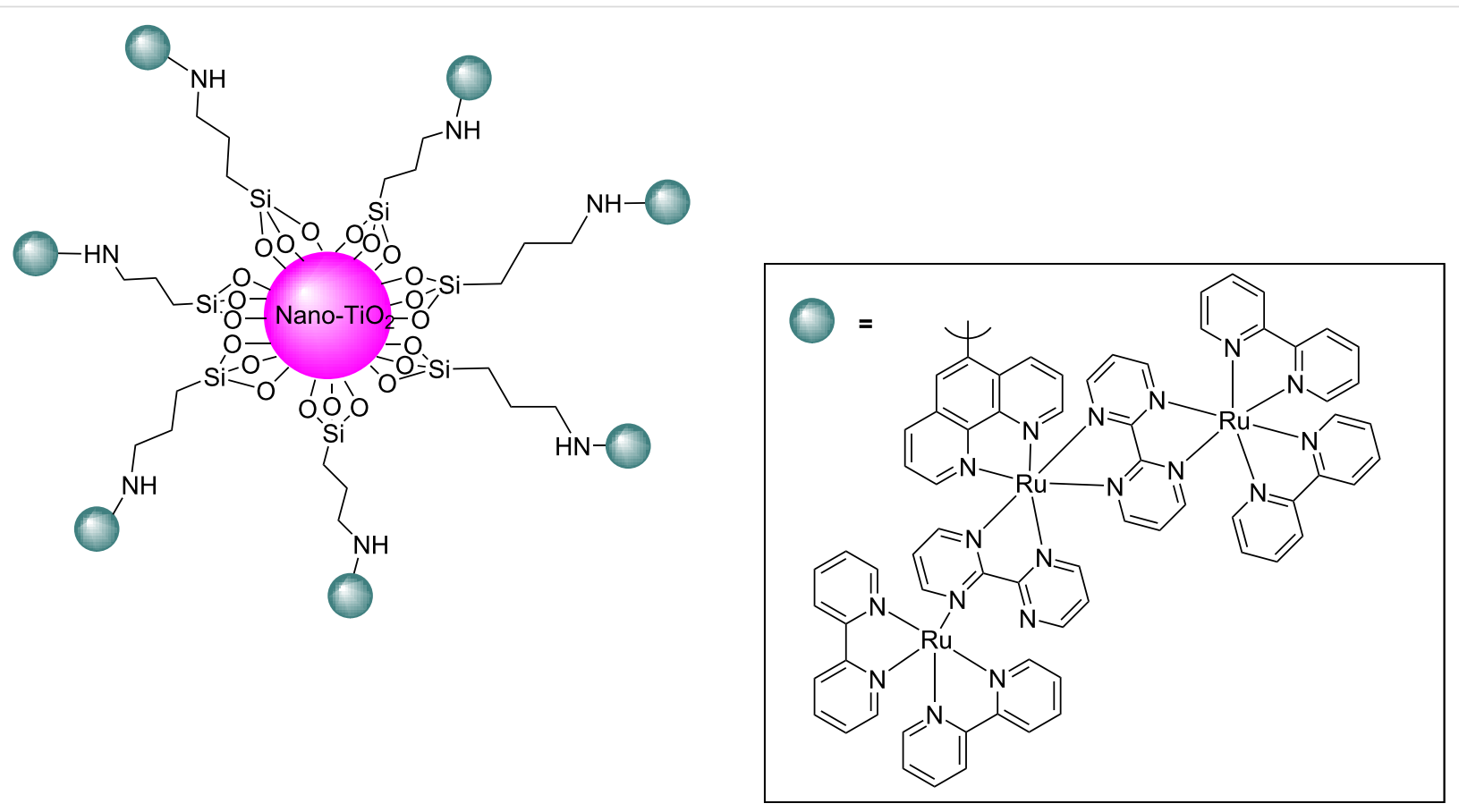

Figure 1: Structure of the $\mathrm{TiO}_{2}$-immobilized ruthenium polyazine complex. 
Table 1: Cyanation of tertiary amines using heterogeneous photoredox catalyst.

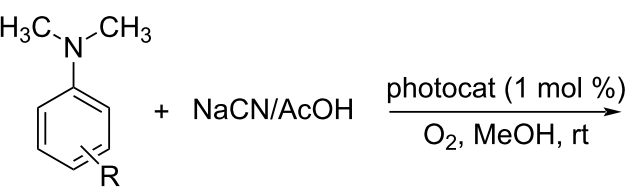<smiles>[R]c1cccc(N(C)CC#N)c1</smiles>

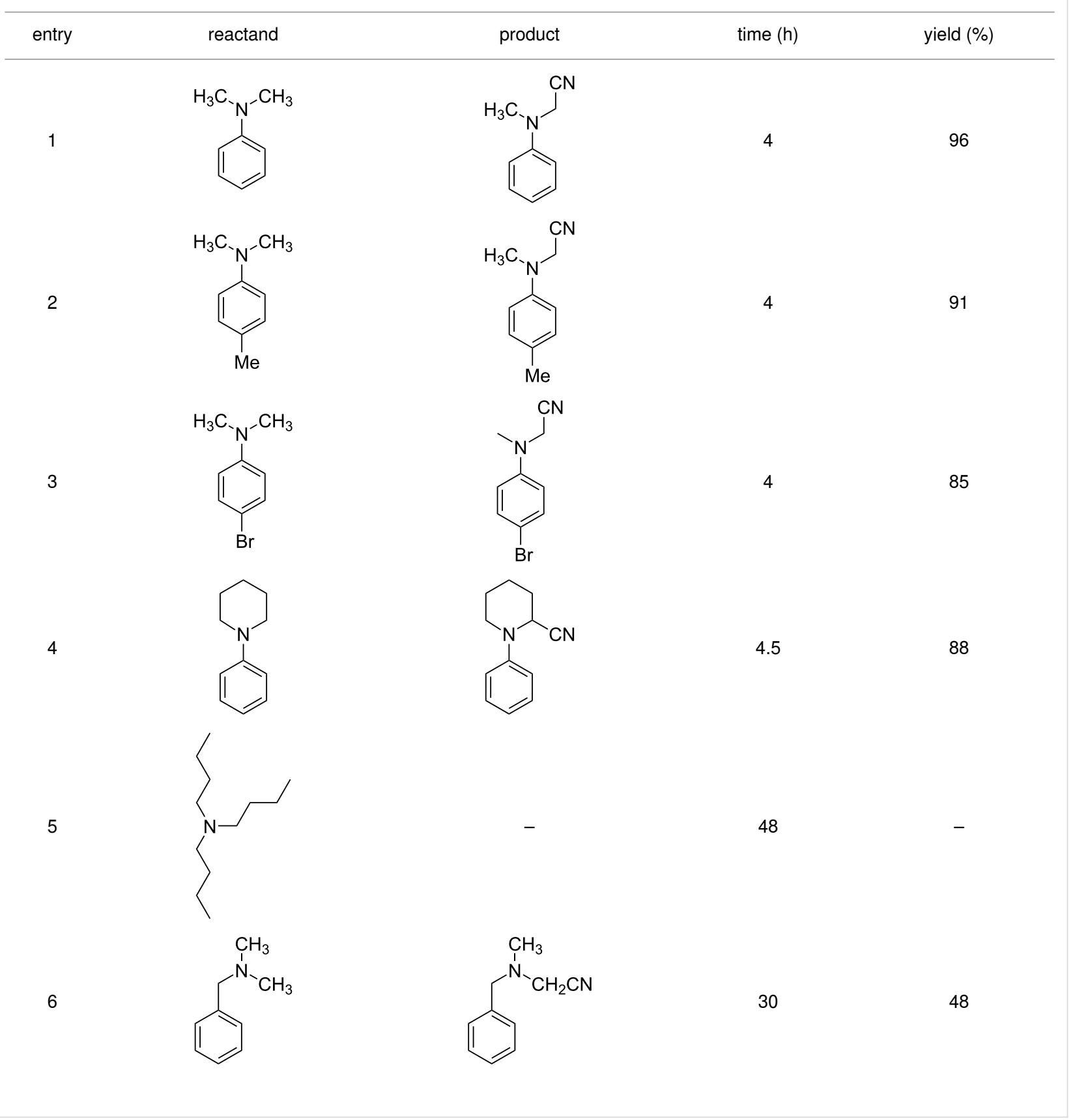

Espino and co-workers developed and characterized a variety of dicationic Ru(II) polypyridyl complexes with 2-(pyridyl)benzimidazole or its $\mathrm{N}$-alkylated derivatives as the ancillary ligands $\left(\mathrm{N}^{\wedge} \mathrm{N}\right)[43]$. The prepared $\mathrm{Ru}(\mathrm{II})$ derivatives were found effi- cient in the synthesis of $\alpha$-amino nitriles from amines via a onepot strategy. This synthetic pathway comprises two consecutive reactions including photooxidation of the amine and the cyanation of resultant aldimine intermediate to afford the $\alpha$-amino 


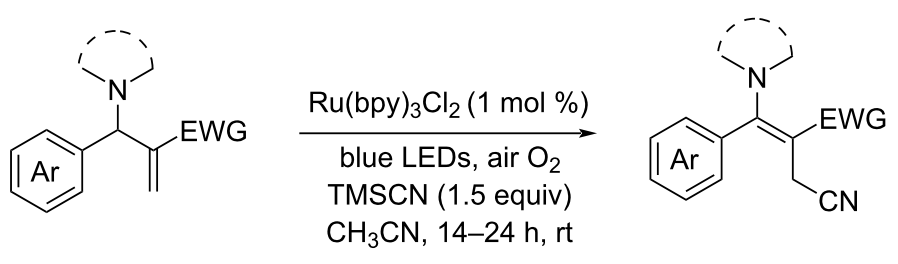<smiles>COC(=O)C(CC#N)=C(c1ccccc1)N1CCCCC1</smiles>

$85 \%$<smiles>COC(=O)C(CC#N)=C(c1ccc(C)cc1)N1CCCCC1</smiles>

$89 \%$<smiles>CC(=O)C(CC#N)=C(c1ccc(Cl)cc1)N1CCCCC1</smiles>

$80 \%$<smiles>COC(=O)C(CC#N)=C(c1ccccc1)N1CCOCC1</smiles>

$80 \%$<smiles>COC(=O)C(CC#N)=C(c1ccc([N+](=O)[O-])cc1)N1CCCCC1</smiles>

$73 \%$<smiles>COC(=O)C(CC#N)=C(c1ccccc1)N1CCCC1</smiles>

$84 \%$

Scheme 16: Visible-light-induced oxidative cyanation of aza-Baylis-Hillman adducts.

$$
\begin{aligned}
& \mathrm{R} \widehat{\mathrm{BF}_{3} \mathrm{~K}}+\operatorname{TsCN} \frac{\left[\mathrm{Ru}(\mathrm{bpy})_{3}\right]\left(\mathrm{PF}_{6}\right)_{2}(2 \mathrm{~mol} \%)}{\mathrm{BI-OAc}(3 \text { equiv), TFA (2 equiv) }} \mathrm{R} \widehat{\mathrm{CN}} \\
& \mathrm{CH}_{2} \mathrm{Cl}_{2} / \mathrm{H}_{2} \mathrm{O} \text {, rt, blue LEDs }
\end{aligned}
$$<smiles>N#CCCc1ccccc1</smiles>

$71 \%$<smiles>N#CCCc1ccc(Cl)cc1</smiles>

$67 \%$<smiles>N#CCCCOc1ccc(Br)cc1</smiles>

$50 \%$<smiles>CCN1C(=O)c2ccccc2C1=O</smiles>

$53 \%$<smiles>CCOC(=O)CCCCC#N</smiles>

$69 \%$

Scheme 17: Synthesis of $1^{\circ}$ alkyl nitriles using $\left[R u(b p y)_{3}\right]\left(\mathrm{PF}_{6}\right)_{2}$ as the photocatalyst.<smiles>N#CC1CCCCC1</smiles><smiles>CC(C)(C)OC(=O)N1CCC(C#N)CC1</smiles>

$77 \%$

$$
\underset{\mathrm{R}^{2}}{\stackrel{\mathrm{R}^{3}}{\mathrm{R}^{1}+} \mathrm{BF} F_{3} \mathrm{~K}}+\operatorname{TsCN} \underset{\begin{array}{c}
\mathrm{BI}-\mathrm{OAc}\left(3 \text { equiv), } \mathrm{CH}_{2} \mathrm{Cl}_{2} / \mathrm{H}_{2} \mathrm{O}, \mathrm{rt}\right. \\
\text { blue LEDs }
\end{array}}{\stackrel{\left[\mathrm{Ru}(\mathrm{bpy})_{3}\right]\left(\mathrm{PF}_{6}\right)_{2}(2 \mathrm{~mol} \%)}{\mathrm{R}^{1}+\mathrm{CN}}} \stackrel{\mathrm{R}^{2}}{\mathrm{R}^{3}}
$$<smiles>CC(C#N)CCOc1cccc(C(=O)c2ccccc2)c1</smiles>

$43 \%$<smiles>CC(C#N)CCOc1ccc(C#N)cc1</smiles>

$87 \%$<smiles>CC1(C#N)CCC(=O)C1</smiles>

$41 \%$<smiles>CC1(C#N)CCCC(=O)C1</smiles>

$45 \%$

Scheme 18: Synthesis of $2^{\circ}$ and $3^{\circ}$ alkyl nitriles using $\left[R u(b p y)_{3}\right]\left(\mathrm{PF}_{6}\right)_{2}$ as the photocatalyst. 
<smiles>O=C1CN(Cc2ccccc2)c2ccccc2N1</smiles>

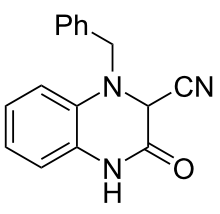

Scheme 19: Photoredox cross coupling reaction.

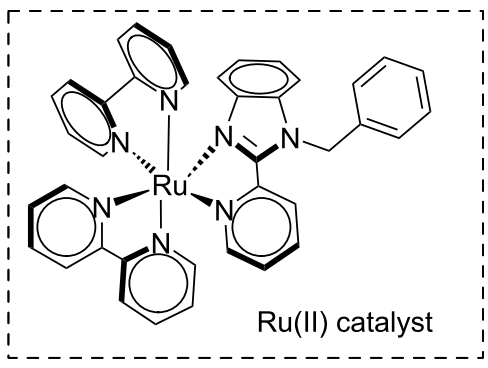

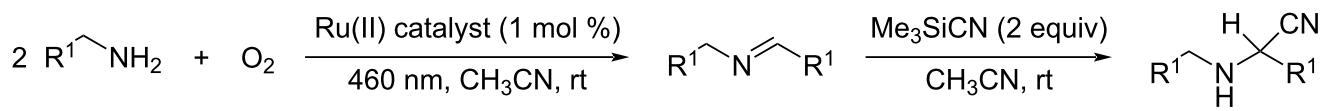<smiles>N#CC(NCc1ccccc1)c1ccccc1</smiles>

$77 \%$<smiles>CCCCCCNC(C#N)CCCCC</smiles>

$46 \%$<smiles>COc1ccc(CNC(C#N)c2ccc(OC)cc2)cc1</smiles>

$72 \%$<smiles>N#CC(NCc1ccc(F)cc1)c1ccc(F)cc1</smiles>

$78 \%$<smiles>CC(NCc1ccc2c(c1)OCO2)c1ccc2c(c1)OCO2</smiles>

$83 \%$<smiles>N#CC1NCCc2ccccc21</smiles>

$67 \%$

Scheme 20: Synthesis of $\alpha$-amino nitriles from amines via a one-pot strategy.

nitriles (Scheme 20). This reaction worked well under ecofriendly conditions with low catalyst loading, and utilizing $\mathrm{O}_{2}$ as green oxidant to give excellent yields of the products. They also disclosed the efficiency of these $\mathrm{Ru}(\mathrm{II})$ complexes in the photooxidation of primary and secondary amines. Moreover, 1-hexylamine worked well in this reaction affording the desired product in moderate to good yields. The efficient transformation of 1-hexylamine proved that this reaction was even applicable to amines with non-activated $\alpha-\mathrm{H}$ atoms. The proposed mechanism for the cyanation step is depicted in Scheme 21.

Chemical synthesis usually needs labor-intensive and tiresome procedures. One of the approaches to overcome these challenges is to perform the reactions in flow [44]. The major advantages of this approach include predictable reaction scaleup, high reproducibility and yields, lower catalyst loading, high product purity, and excellent selectivity.

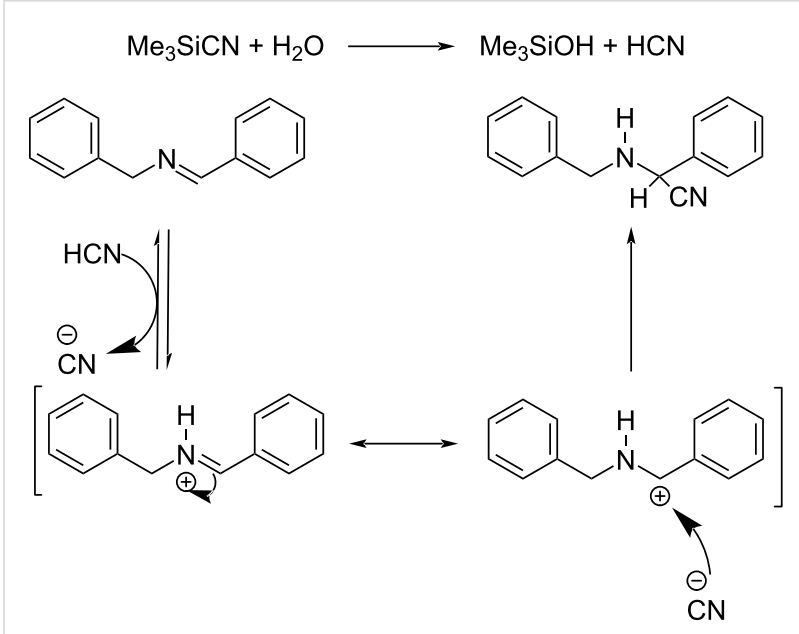

Scheme 21: Proposed mechanistic pathway for the cyanation of the aldimine intermediate. 
A visible-light-promoted Strecker-type functionalization of $\mathrm{N}$-aryl-substituted tetrahydroisoquinolines under flow conditions was reported (Scheme 22) [45]. The cyanating agent utilized was trimethylsilyl cyanide (TMSCN) in acetonitrile solvent under CFL light irradiation.

\section{Miscellaneous}

An efficient methodology for the synthesis of $\alpha$-aminonitriles via the one-pot coupling of aldehydes, amines and trimethylsilyl cyanide was reported [46]. This reaction was catalyzed by $\mathrm{RuCl}_{3}$ and used acetonitrile as solvent (Scheme 23). Both aromatic and aliphatic aldehydes performed well and gave the desired products in good yields. At the same time ketones were found less active in this strategy. The operational simplicity and high yield of products are the prominent characteristics of this reaction.

In 2008, Bhanage et al. developed a novel methodology for the synthesis of alkyl iodides/nitriles using ruthenium tris(2,2,6,6tetramethyl-3,5-heptanedionate) $\left(\mathrm{Ru}(\mathrm{TMHD})_{3}\right)$ as the catalyst (Scheme 24) [47]. This catalyst was found highly efficient in the hydrogenation, iodination, and cyanation reaction of carbonyl compounds under environmentally benign conditions. This method provides an efficient synthetic route towards alkyl iodides and nitriles in one pot. Carbonyl compounds such as cinnamaldehyde, acetophenone, and cyclohexanone etc. were well tolerated in this reaction and afforded the corresponding nitriles in moderate to good yields.

Zhang and co-workers developed an efficient methodology for the synthesis of cyanated isoxazolines from the corresponding alkenyl oximes under mild reaction conditions (Scheme 25) [48]. The dual role of tert-butyl nitrite as oxidant and as a nitrogen source further enhanced the significance of this method. $\left[\mathrm{RuCl}_{2} \text { (p-cymene) }\right]_{2}$ was identified as the best choice of catalyst. Differently substituted alkenyl oximes with aryl, heteroaryl, and alkyl substituents performed well in this reaction. The major advantage of this method is the formation of $\mathrm{C}-\mathrm{O}$ and $\mathrm{C} \equiv \mathrm{N}$ bonds in a single-step. The proposed mechanism is depicted in Scheme 26.

Xiao and co-workers developed an environmentally benign strategy for the oxidative cyanation of differently substituted alcohols using a manganese oxide nanorod-supported ruthenium catalyst (Scheme 27) [49]. They also evaluated the efficiency of other metals such as $\mathrm{Au}, \mathrm{Pt}, \mathrm{Pd}, \mathrm{Rh}, \mathrm{Ag}$, and Fe and found that they were less efficient compared to $\mathrm{Ru}$. The benzylic alcohols showed higher reactivity than aliphatic alco-

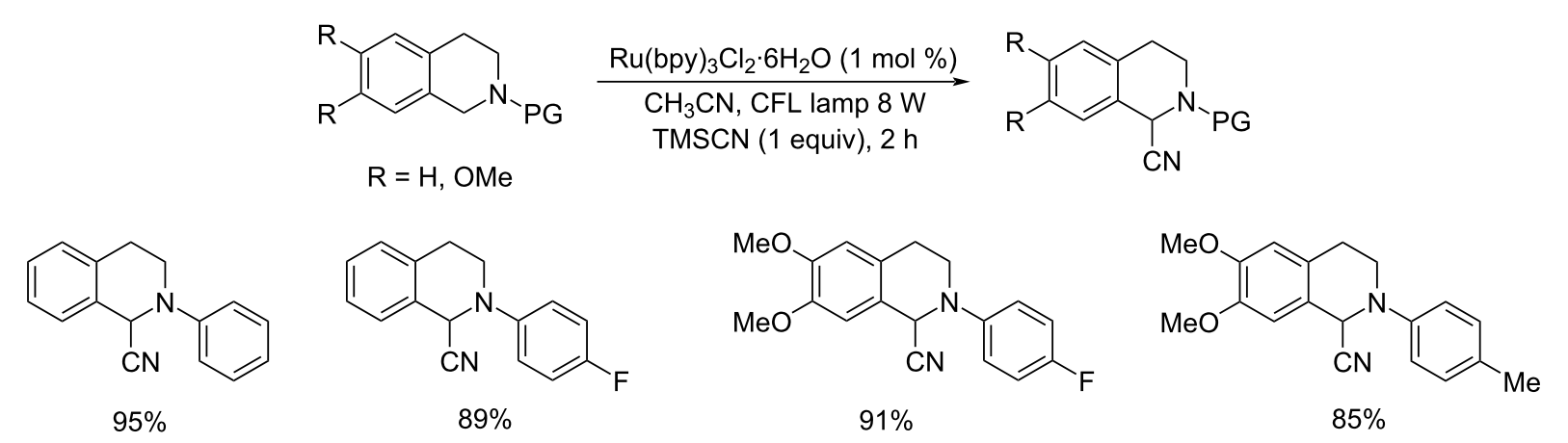

Scheme 22: Strecker-type functionalization of $\mathrm{N}$-aryl-substituted tetrahydroisoquinolines under flow conditions.

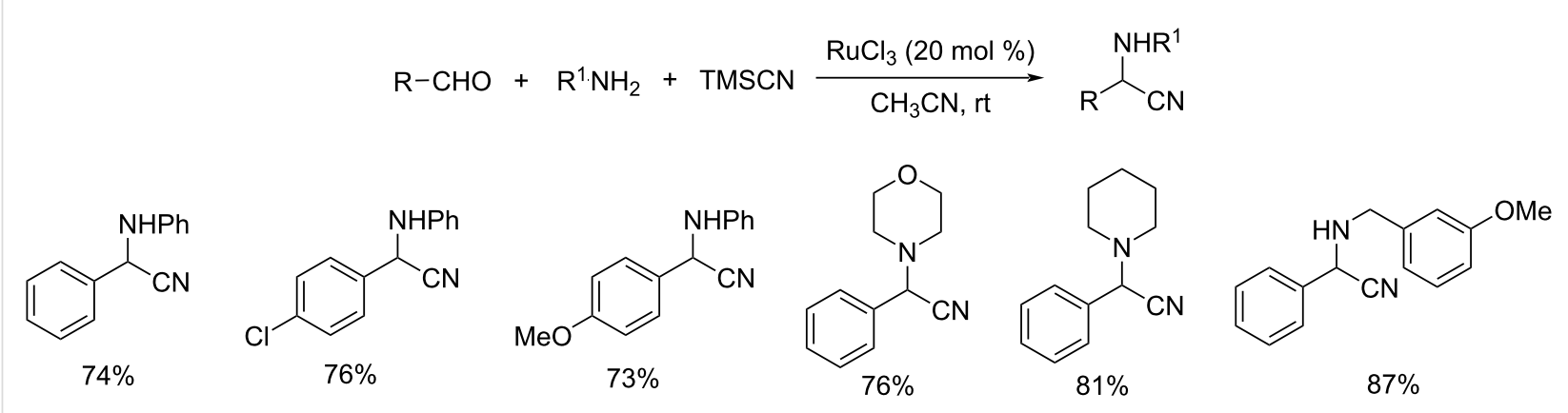



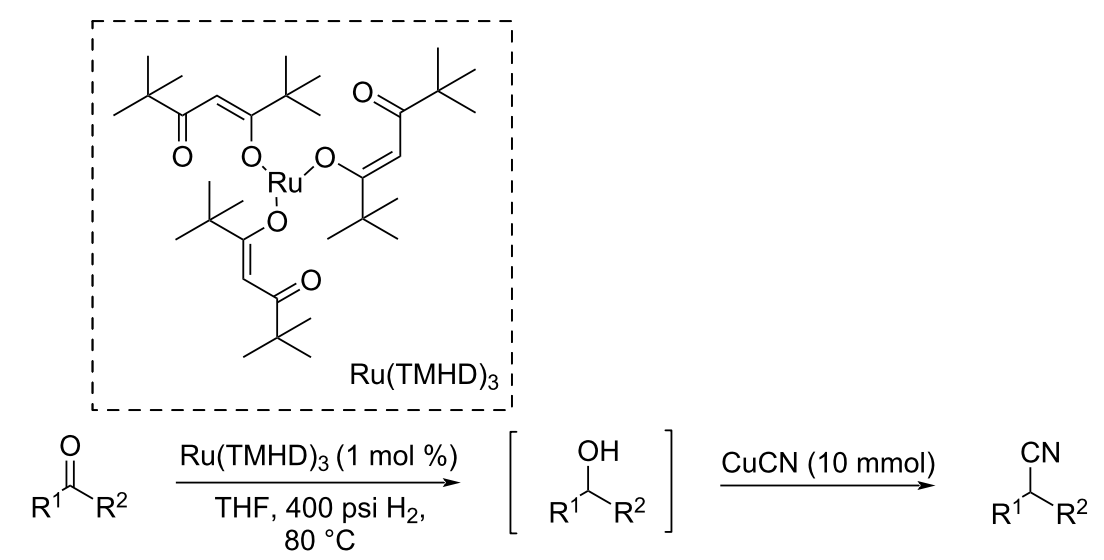<smiles>N#CCc1ccccc1</smiles>

$84 \%$<smiles>N#CC(c1ccccc1)c1ccccc1</smiles>

$75 \%$<smiles>N#CC/C=C/c1ccccc1</smiles>

$58 \%$<smiles>CC(C#N)c1ccccc1</smiles>

$78 \%$

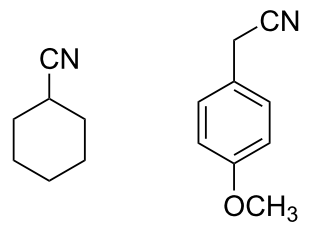

$70 \% \quad 82 \%$

Scheme 24: Synthesis of alkyl nitriles using $\left(\mathrm{Ru}(\mathrm{TMHD})_{3}\right)$ as the catalyst.

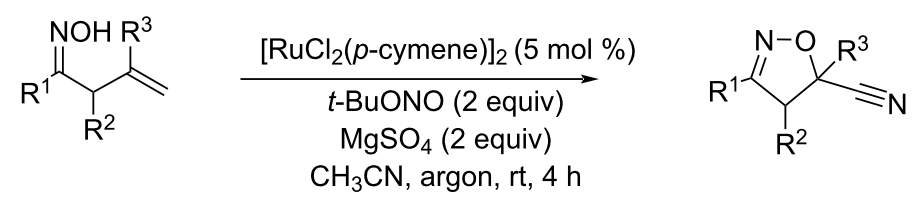<smiles>N#CC1CC(c2ccccc2)=NO1</smiles>

$86 \%$<smiles>N#CC1CC(c2ccco2)=NO1</smiles>

$76 \%$<smiles>N#CC1CC(c2cc(F)cc(F)c2)=NO1</smiles>

$91 \%$<smiles>N#CC1CC(c2ccc3ccccc3c2)=NO1</smiles>

$78 \%$

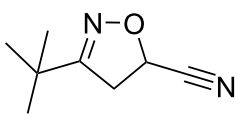

$74 \%$<smiles>Cc1ccc(C2=NOC(C#N)C2)cc1</smiles>

$84 \%$

Scheme 25: Synthesis of cyanated isoxazolines from alkenyl oximes catalyzed by $\left[\mathrm{RuCl}_{2}(p \text {-cymene })\right]_{2}$ in the presence of tert-butyl nitrite.

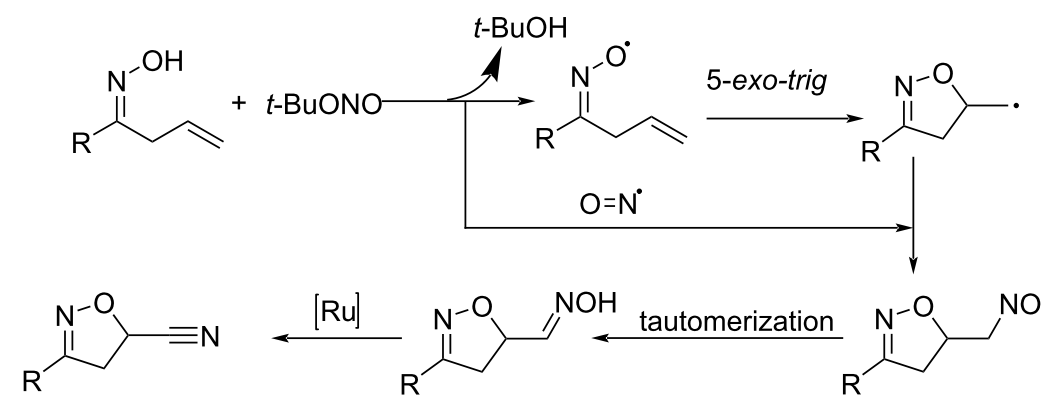

Scheme 26: Proposed mechanism for the synthesis of cyanated isoxazolines from alkenyl oximes. 


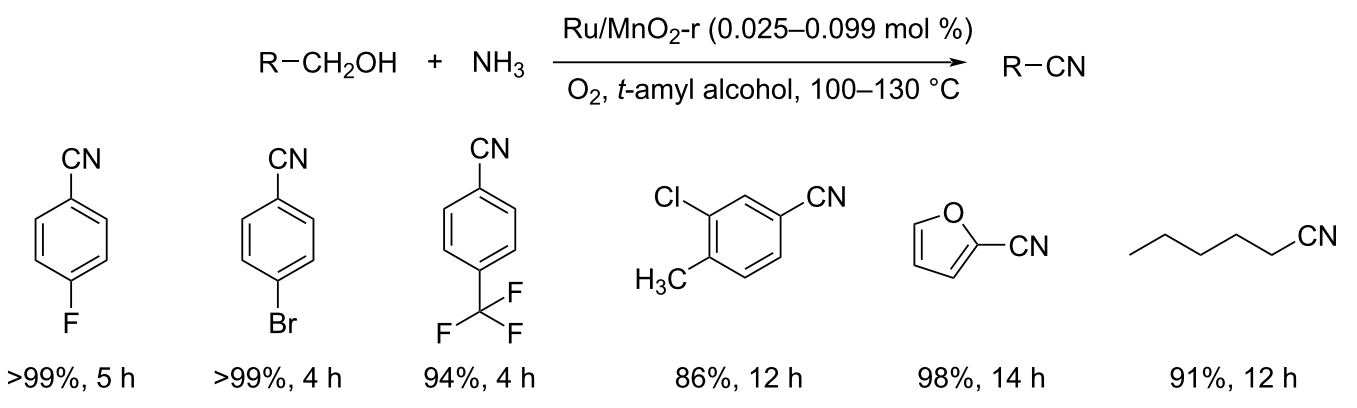

Scheme 27: Oxidative cyanation of differently substituted alcohols.

hols towards this methodology. Moreover, this protocol worked well for differently substituted heterocyclic alcohols and afforded the products in excellent yields. The authors also conducted various experimental and theoretical studies to analyze the reaction mechanism. The proposed mechanism begins with the oxidative dehydrogenation of the alcohol to afford the aldehyde which undergoes condensation with ammonia to give the corresponding imine. Finally, oxidative dehydrogenation results in the formation of the nitrile.

\section{Conclusion}

This review summarizes the recent progress in ruthenium-catalyzed cyanation reactions. Due to the wide application of nitrile compounds in pharmaceutical and biological fields, cyanation reactions have achieved significant progress in recent times.

Transition-metal-catalyzed cyanation reactions have emerged as an alternative approach to conventional cyanation strategies. Nowadays ruthenium has gained much acceptance owing to its wide range of oxidation states and ability to form a large number of complexes. From our discussion it is evident that the most commonly used cyanating reagents include highly toxic compounds such as $\mathrm{K}_{4}\left[\mathrm{Fe}(\mathrm{CN})_{6}\right], \mathrm{NaCN}, \mathrm{CuCN}$, TMSCN etc. However, some of the reported works involve the use of safer and greener cyanation sources like NCTS, acetone cyanohydrin, ethyl cyanoformate etc.

Our studies disclosed that many of the reports were mainly focusing on the oxidative cyanation of tertiary amines. Extensive research was carried out in the cyanation of tertiary amines using different oxidants such as $\mathrm{O}_{2}, \mathrm{H}_{2} \mathrm{O}_{2}$, and TBHP. Ruthenium was also found to be effective in the cyanation of arenes and heteroarenes with high functional group tolerance. Some of the suggested methods utilized photoredox catalysts and thus offer new avenues towards greener and economical nitrile synthesis.

In spite of these advancements, the use of toxic cyanating agents like $\mathrm{NaCN}$ in almost all the methods remains as a limita- tion in this area. The use of non-toxic and environment friendly cyanating agents such as NCTS, acetone cyanohydrin, ethyl cyanoformate etc needs more attention in future. Scientists can also focus more on cyanation reactions using photoredox catalyst.

The larger availability of reactive complexes of ruthenium and the high reusability and easy separation procedures of heterogeneous catalysts have proven the fact that this metal serve as highly effective catalyst for a wide range of organic transformations. It will surely motivate the scientific community to develop more environmentally benign cyanation reactions using ruthenium in future.

\section{Funding}

TA, CMA, and PVS thank the Council of Scientific and Industrial Research (CSIR New Delhi) for the award of research fellowships. GA thanks the Kerala State Council for Science Technology \& Environment (KSCSTE, Trivandrum) for financial support in the form of a research grant (No. 341/2013/ KSCSTE dated 15.03.2013).

\section{ORCID ${ }^{\circledR}$ iDs}

Thaipparambil Aneeja - https://orcid.org/0000-0001-5284-2961 Cheriya Mukkolakkal Abdulla Afsina https://orcid.org/0000-0001-8076-8578

Padinjare Veetil Saranya - https://orcid.org/0000-0003-1874-1395

Gopinathan Anilkumar - https://orcid.org/0000-0002-7907-5616

\section{References}

1. Ding, R.; Liu, Y.; Han, M.; Jiao, W.; Li, J.; Tian, H.; Sun, B. J. Org. Chem. 2018, 83, 12939-12944. doi:10.1021/acs.joc.8b02190

2. Enders, D.; Shilvock, J. P. Chem. Soc. Rev. 2000, 29, 359-373. doi:10.1039/a908290e

3. Strecker, A. Justus Liebigs Ann. Chem. 1850, 75, 27-45. doi:10.1002/jlac.18500750103

4. Iyer, M. S.; Gigstad, K. M.; Namdev, N. D.; Lipton, M. J. Am. Chem. Soc. 1996, 118, 4910-4911. doi:10.1021/ja952686e 
5. Rafiee, E.; Azad, A. Synth. Commun. 2007, 37, 1127-1132. doi:10.1080/00397910701198914

6. Rafiee, E.; Rashidzadeh, S.; Azad, A. J. Mol. Catal. A: Chem. 2007, 261, 49-52. doi:10.1016/j.molcata.2006.07.058

7. Haddenham, D.; Pasumansky, L.; DeSoto, J.; Eagon, S.; Singaram, B. J. Org. Chem. 2009, 74, 1964-1970. doi:10.1021/j08023329

8. Knight, J. A.; Zook, H. D. J. Am. Chem. Soc. 1952, 74, 4560-4562. doi:10.1021/ja01138a031

9. Demko, Z. P.; Sharpless, K. B. J. Org. Chem. 2001, 66, 7945-7950. doi:10.1021/jo010635w

10. Garduño, J. A.; Garcıa, J. J. ACS Catal. 2015, 5, 3470-3477. doi:10.1021/acscatal.5b00348

11. Allen, C. L.; Lapkin, A. A.; Williams, J. M. J. Tetrahedron Lett. 2009, 50, 4262-4264. doi:10.1016/j.tetlet.2009.05.021

12. Pongratz, A. Monatsh. Chem. 1927, 48, 585-591. doi:10.1007/bf01518076

13. Nielsen, M. A.; Nielsen, M. K.; Pittelkow, T. Org. Process Res. Dev. 2004, 8, 1059-1064. doi:10.1021/op0498823

14. Koelsch, C. F.; Whitney, A. G. J. Org. Chem. 1941, 6, 795-803. doi:10.1021/j001206a002

15. Saranya, S.; Neetha, M.; Aneeja, T.; Anilkumar, G. Adv. Synth. Catal. 2020, 362, 4543-4551. doi:10.1002/adsc.202000827

16. Pawar, A. B.; Chang, S. Org. Lett. 2015, 17, 660-663. doi:10.1021/ol503680d

17. Kanchana, U. S.; Mathew, T. V.; Anilkumar, G. J. Organomet. Chem. 2020, 920, 121337. doi:10.1016/j.jorganchem.2020.121337

18. Neetha, M.; Afsina, C. M. A.; Aneeja, T.; Anilkumar, G. RSC Adv. 2020, 10, 33683-33699. doi:10.1039/d0ra05960a

19. Li, Z.-I.; Sun, K.-k.; Cai, C. Org. Chem. Front. 2018, 5, 1848-1853. doi:10.1039/c8qo00322j

20. Soumya, P. K.; Vaishak, T. B.; Saranya, S.; Anilkumar, G. Appl. Organomet. Chem. 2021, 35, e6340. doi:10.1002/aoc.6340

21. Fairoosa, J.; Shamna, S.; Neetha, M.; Anilkumar, G. Appl. Organomet. Chem. 2021, 35, e6356. doi:10.1002/aoc.6356

22. Hughes, T. V.; Cava, M. P. J. Org. Chem. 1999, 64, 313-315. doi:10.1021/jo981924w

23. Kahne, D.; Collum, D. B. Tetrahedron Lett. 1981, 22, 5011-5014. doi:10.1016/s0040-4039(01)92406-2

24. Davis, W. A.; Cava, M. P. J. Org. Chem. 1983, 48, 2774-2775. doi:10.1021/jo00164a030

25. Wheland, R. C.; Martin, E. L. J. Org. Chem. 1975, 40, 3101-3109. doi:10.1021/jo00909a019

26. Maas, G. Chem. Soc. Rev. 2004, 33, 183-190. doi:10.1039/b309046a

27. Naota, T.; Takaya, H.; Murahashi, S.-I. Chem. Rev. 1998, 98 , 2599-2660. doi:10.1021/cr9403695

28. Verma, S.; Jain, S. L.; Sain, B. ChemCatChem 2011, 3, 1329-1332. doi:10.1002/cctc.201100111

29. Reddy, K. H. V.; Satish, G.; Reddy, V. P.; Anil Kumar, B. S. P.; Nageswar, Y. V. D. RSC Adv. 2012, 2, 11084-11088. doi:10.1039/c2ra21630b

30. Kumar, S.; Kumar, P.; Jain, S. L. RSC Adv. 2013, 3, 24013-24016. doi:10.1039/c3ra44051f

31. Wang, X.; Xiao, R.; Ai, J.; Cai, M. J. Chem. Res. 2017, 41, 576-580. doi:10.3184/174751917x15064232103065

32. Murahashi, S.-I.; Komiya, N.; Terai, H.; Nakae, T. J. Am. Chem. Soc. 2003, 125, 15312-15313. doi:10.1021/ja0390303

33. Murahashi, S.-I.; Komiya, N.; Terai, H. Angew. Chem., Int. Ed. 2005, 44, 6931-6933. doi:10.1002/anie.200501496

34. Murahashi, S.-I.; Nakae, T.; Terai, H.; Komiya, N. J. Am. Chem. Soc. 2008, 130, 11005-11012. doi:10.1021/ja8017362
35. Verma, S.; Jain, S. L.; Sain, B. Catal. Lett. 2011, 141, 882-885. doi:10.1007/s10562-011-0582-6

36. Khorshidi, A. Chin. Chem. Lett. 2012, 23, 903-906. doi:10.1016/j.cclet.2012.06.030

37. Liu, W.; Ackermann, L. Chem. Commun. 2014, 50, 1878-1881. doi:10.1039/c3cc49502g

38. Mishra, A.; Vats, T. K.; Deb, I. J. Org. Chem. 2016, 81, 6525-6534. doi:10.1021/acs.joc.6b01148

39. Kumar, P.; Varma, S.; Jain, S. L. J. Mater. Chem. A 2014, 2 , 4514-4519. doi:10.1039/c3ta14783e

40. Srivastava, V. P.; Yadav, A. K.; Yadav, L. D. S. Tetrahedron Lett. 2014, 55, 1788-1792. doi:10.1016/j.tetlet.2014.01.121

41. Dai, J.-J.; Zhang, W.-M.; Shu, Y.-J.; Sun, Y.-Y.; Xu, J.; Feng, Y.-S.; Xu, H.-J. Chem. Commun. 2016, 52, 6793-6796. doi:10.1039/c6cc01530a

42. Akula, P. S.; Hong, B.-C.; Lee, G.-H. RSC Adv. 2018, 8, 19580-19584. doi:10.1039/c8ra03259a

43. Echevarría, I.; Vaquero, M.; Quesada, R.; Espino, G. Inorg. Chem. Front. 2020, 7, 3092-3105. doi:10.1039/d0qi00580k

44. Bédard, A.-C.; Adamo, A.; Aroh, K. C.; Russell, M. G.; Bedermann, A. A.; Torosian, J.; Yue, B.; Jensen, K. F.; Jamison, T. F. Science 2018, 361, 1220-1225. doi:10.1126/science.aat0650

45. Filipović, A.; Džambaski, Z.; Vasiljević-Radović, D.; Bondžić, B. P. Org. Biomol. Chem. 2021, 19, 2668-2675. doi:10.1039/d0ob02582h

46. De, S. K. Synth. Commun. 2005, 35, 653-656. doi:10.1081/scc-200050347

47. Bhor, M. D.; Panda, A. G.; Nandurkar, N. S.; Bhanage, B. M. Tetrahedron Lett. 2008, 49, 6475-6479. doi:10.1016/j.tetlet.2008.09.002

48. Wang, D.-J.; Chen, B.-Y.; Wang, Y.-Q.; Zhang, X.-W. Eur. J. Org. Chem. 2018, 1342-1346. doi:10.1002/ejoc.201701651 49. Wang, H.; Xu, D.; Guan, E.; Wang, L.; Zhang, J.; Wang, C.; Wang, S.; Xu, H.; Meng, X.; Yang, B.; Gates, B. C.; Xiao, F.-S. ACS Catal. 2020, 10, 6299-6308. doi:10.1021/acscatal.0c00485

\section{License and Terms}

This is an open access article licensed under the terms of the Beilstein-Institut Open Access License Agreement (https://www.beilstein-journals.org/bjoc/terms), which is identical to the Creative Commons Attribution 4.0 International License (https://creativecommons.org/licenses/by/4.0). The reuse of material under this license requires that the author(s), source and license are credited. Third-party material in this article could be subject to other licenses (typically indicated in the credit line), and in this case, users are required to obtain permission from the license holder to reuse the material.

The definitive version of this article is the electronic one which can be found at: https://doi.org/10.3762/bjoc.18.4 